\title{
JÓVENES DELGADAS, BELLAS Y BLANCAS: LA PRODUCCIÓN DEL CUERPO JUVENIL EN LA PUBLICIDAD. EL CASO DE REVISTA MARGARITA (1930-1940)
}

\author{
MARCELA SAA ESPINOZA*
}

\begin{abstract}
RESUMEN
En este artículo se analiza la construcción o configuración de una idea de juventud en Chile, a partir del análisis de la representación del cuerpo juvenil femenino en una revista chilena que circuló desde los años 1930 llamada Margarita. El análisis contempló la interpretación de imágenes publicitarias a partir de una lectura semiótica que relevará su dimensión textual y visual. En este artículo se presentan los resultados que evidencian los principales atributos que caracterizaron al cuerpo joven femenino y se transformaron en indiscutibles hasta la actualidad, así como las formas en que la publicidad comunicó y fijó dichos atributos a partir de estrategias que amenazaban o gratificaban la obtención de estos cuerpos.
\end{abstract}

PALABRAS CLAVE: JUVENTUD, CUERPO, IMÁGENES PUBLICITARIAS

* Antropóloga. Magíster en Estudios de la Imagen Universidad Alberto Hurtado, Chile. Este artículo se enmarca en el Proyecto Fondecyt No11110373: «Genealogía de lo juvenil en Chile en el Siglo XX».

E-Mail: marcelasaae@gmail.com. 


\title{
A PRODUÇÃO DO CORPO FEMININO JUVENIL NA PUBLICIDADE CHILENA. \\ O CASO DA REVISTA MARGARITA (1930-1940)
}

\begin{abstract}
RESUMO
Neste artigo é analisada a construção ou configuração de uma ideia de juventude no Chile, a partir da análise da representação do corpo feminino juvenil em uma revista chilena que circulou a partir dos anos 30 chamada Margarita. A análise contemplou a interpretação de imagens publicitárias a partir de uma leitura semiótica que revelará sua dimensão textual e visual. Neste artigo são apresentados os resultados que evidenciam os principais atributos que caracterizaram o corpo feminino jovem e que se transformaram em indiscutíveis até a atualidade, assim como as formas em que a publicidade comunicou e fixou estes atributos utilizando estratégias que ameaçavam ou gratificavam a obtenção destes corpos.
\end{abstract}

PALAVRAS CHAVE: JUVENTUDE, CORPO, IMAGENS PUBLICITÁRIAS

\section{THE PRODUCTION OF THE YOUNG FEMALE BODY IN CHILEAN ADVERTISING. THE CASE OF MARGARITA MAGAZINE (1930-1940)}

\begin{abstract}
The following article provides an insight into the construction or configuration of an ideal of youth in Chile on the basis of the analysis of the representation of the young female body instilled by the Chilean magazine Margarita, in circulation from the 1930s. The analysis included the interpretation of advertising images through a semiotic reading focused on revealing their textual and visual dimension. The results of this article highlight the main ideal attributes in the young female body, which eventually became undisputed standards until today, as well as the means and strategies used by advertising for spreading, encouraging and stilling such ideal of body.
\end{abstract}

KEY WORDS: YOUTH, BODY, ADVERTISING IMAGES 


\section{INTRODUCCIÓN}

LA JUVENTUD, LEJOS DE ser una evidencia natural o un momento del ciclo vital por el que los seres humanos transitamos, ha sido considerada, en los campos de las ciencias sociales y humanas, una construcción sociocultural. En ese sentido la juventud se construye y varía según los tiempos y lugares de su producción. A partir del análisis de imágenes publicitarias que forman parte de la expresión de cultura popular y de consumo que se instaló en Chile a principios del Siglo XX, se presenta en este artículo el resultado del análisis de imágenes publicitarias $^{1}$ de la revista chilena Margarita durante la década de 1930. Con ello, se espera conocer cómo se representaron y circularon ideas sobre el cuerpo de la juventud femenina, y cómo así se construye una determinada idea de juventud en el país.

El artículo está dividido en cuatro partes. En la primera parte se señalan las miradas teóricas de base que estuvieron presentes en el análisis y con las que se comprende el objeto de estudio. En un segundo momento, se indican las características del material estudiado; es decir la revista, la publicidad y la forma como se accedió a la información y resultados. En un tercer momento se presentan los resultados sobre qué atributos que se usaron para generar una idea de cuerpo joven y femenino en la publicidad. Por último, se presentan las dos estrategias disciplinares que se detectaron en la comunicación y mensajes de la publicidad de la revista Margarita durante la década de 1930.

\section{JUVENTUD CUERPO Y GÉNERO: MIRADAS TEÓRICAS}

La juventud como categoría de análisis social — desarrollada desde las ciencias sociales y humanas - es definida como una construcción cultural, social e históricamente situada (Feixa 1998; Aguilera, 2009; Toro, 2012). Para disciplinas como la antropología o la historia, la condición juvenil no remite a una condición biológica universal sino más bien a formas de adscripción social definida por elementos culturales y relaciones sociales dentro de las estructuras reales e imagina-

1 Durante el desarrollo del artículo serán identificadas las imágenes que ilustran los casos que analizamos y presentamos. El soporte virtual de las imágenes si bien no es indispensable para la lectura del presente artículo, permitirá al lector profundizar en la comprensión e interés por la temática. 
rias del tiempo y espacio en las que se produce. Como variable del análisis social, la juventud se caracteriza por una serie de atributos definidos en la modernidad, los que se han producido y asignado por instituciones (Iglesia, Escuela, Estado, Industria) por las disciplinas y ciencias (psiquiatría, medicina, sexología, antropología, sociología, entre otras), y que han funcionado como motores discursivos e ideológicos fundamentales para comprender qué es y qué fue la juventud.

Los atributos funcionan como caracteristicas universalizantes de lo juvenil y se han naturalizado en el discurso social hasta llegar a una especie de «sentido común» de cómo se es y quiénes son los jóvenes. Creemos que rastrear y analizar la construcción de la juventud es un ejercicio posible a partir del reconocimiento de diferentes dimensiones de lo sociocultural que tienen la capacidad de dar cuenta de sus inicios, desarrollos y estabilidades durante la modernidad. Para nuestro caso, hemos decidido indagar en la conformación del cuerpo juvenil, en la medida en que el cuerpo es una dimensión empírica cargada de significados sociales, ideológicos y políticos, y que por estas características se ubica en un espacio social más o menos definido (Le Breton, 2002).

Es relevante señalar que la centralidad del concepto «cuerpo» como parte de una matriz discursiva configuradora de lo juvenil ha estado presente en las disciplinas y saberes psicobiológicos, desde Stanley Hall (1904) y la distinción de los temperamentos de los adolescentes, hasta las problematizaciones de identidad sexual de travestis en los actuales estudios de juventud a los cuales hace referencia $\mathbf{M}$. Urtega (2010). Sin embargo, el cuerpo así como otras categorías sociales, muchas veces solo parece constatarse y la materialidad queda limitada a un cuerpo biológico que si bien se reconoce, es atravesado por prácticas y discursos normalizadores. $\mathrm{Al}$ menos desde el campo de la juventud no ha sido un eje de análisis primordial para elaborar una concepción acerca de cómo se ha construido una idea de juventud.

Nuestra decisión de poner atención al cuerpo como lugar desde donde se articula y despliega un saber y confección de juventud, busca evidenciar formas en que una perspectiva teórica como la biopolítica (Foucault, 2005) puede orientar el análisis para no solo constatar sino también interrogar por aquellas configuraciones del cuerpo joven. Así se reconoce la importancia y centralidad que tiene el disciplinamiento del cuerpo para el control de la población y también en qué formas las resistencias que emergen de ellos constituyen una materialidad y discursividad que se objetivará para dar cuenta de quiénes son los jóvenes. De esta forma, sostenemos que un análisis de las representaciones 
de cuerpos jóvenes en imágenes, permitirá conocer, interpretar y señalar aquellos disciplinamientos y regulaciones necesarias en la construcción de un cuerpo juvenil, femenino y moderno en la sociedad chilena de principios del siglo XX. En ese sentido la pregunta por el cuerpo, sus contornos y formas de ser representado, es una construcción y no un fenómeno natural, se transforma en la guía y manera de interrogar una materialidad y discursividad que parece objetivada y sin historia incluso dentro de los propios estudios de juventud.

Debemos señalar también que será el cuerpo de las jóvenes, más que el de los varones, mayormente invisibilizado en el desarrollo del campo de juventud, por lo que presentaremos aquí un análisis con mayor atención al cuerpo femenino para tratar de compensar estos vacíos en el campo. El género en los estudios de juventud, así como la generación para los estudios de género, ha sido una relación de invisibilizaciones continuas, que al menos en el caso chileno tienen como resultado la baja sistematización sobre estas temáticas. Como señalarán Ángela McRobbie y Jenny Garber (2010), ya en los años setenta en un texto clásico de los estudios culturales, las jóvenes no necesariamente eran marginadas sino «estructuralmente distintas», en la medida que viven en un mundo dominado por la masculinidad. De esta manera McRobbie evidencia que buena parte de los investigadores ha buscado en espacios donde se imposibilita observar chicas o jóvenes activamente, invisibilizando los espacios donde habitan y crean sus propias formas de socialización definidos en buena medida por su condición de género.

De esa forma comprendemos que el género como otra variable del análisis social, es de fundamental importancia para concebir de manera compleja lo que significó la construcción de la juventud (Urteaga, 2010). Y de esta misma forma, es también importante reconocer que el desplazamiento a otros lugares, como los del consumo, por ejemplo, son relevantes para pensar la juventud femenina como un actor activo. Aquí debemos señalar que en el ejercicio de indagar cómo se configura una idea de juventud, debemos superar el supuesto que al tomar el consumo, la industria y sus productos como fuentes de investigación, no podamos hacerlo antes de la década de 1960 como lo sostendrán algunos autores (Reguillo, 2003). Asumir el riesgo de trabajar con materiales previo a 1960, permite visibilizar otros productos como revistas (y las propias imágenes) como fuentes centrales de la cultura y en espacios pertinentes para este tipo de análisis. 


\section{LAS JÓVENES DE MARGARITA: JUVENTUD E IMÁGENES PUBLICITARIAS}

Margarita fue una revista chilena que estuvo en circulación entre los años 1934 y 1952, y como reconocen García Huidobro y Escobar (2012) es una de las revistas dirigidas al público femenino de mayor alcance de la primera mitad del siglo XX. Fue producida por editorial Zig Zag, su frecuencia era semanal y en los primeros años se distribuía principalmente en Santiago y Valparaíso, pero posteriormente se distribuyó nacional e internacionalmente. La revista, que aparecía todos los jueves, estaba ordenada por secciones que contenía novela por entrega o capítulos, reportajes dedicados al hogar, la moda, el amor, la belleza y la juventud y páginas completas de publicidad. Es importante señalar que Margarita es una revista que no debe pensarse solo con una segmentación de público dirigido a lo «femenino», sino también a un grupo juvenil cada vez más identificado por el mercado, por lo que no es de extrañar un uso abundante de imágenes publicitarias destinadas al interés de las jóvenes y adultas, o incluso tomándolas como representación por excelencia para la promoción de los más diversos artículos.

En cuanto al mercado más general de revistas para la juventud, es posible decir a partir de la sistematización de dichos materiales, que al menos en Chile no existe una presencia significativa de medios escritos producidos desde la industria cultural durante las primeras décadas del siglo hacia los jóvenes, y serán las revistas y/o boletines independientes o con adscripciones estudiantiles los que se enfocan y producen medios dirigidos hacía el grupo juvenil. Esta situación cambia en los años treinta, época donde se produjeron una mayor cantidad de revistas juveniles provenientes de la industria y los sectores independientes. Al mismo tiempo, desde la industria publicitaria y a partir de los más diversos productos, se construyó un fuerte discurso sobre los jóvenes y la juventud, quienes fueron tomados como modelos y público objetivo de consumo. De esta forma consideramos que el análisis a las piezas publicitarias de este período son significativas para dar cuenta de aquellos inicios en la representación del cuerpo joven en la publicidad.

Es posible sostener que la utilización de imágenes para fines vinculados al consumo fue un dispositivo capaz de transmitir determinadas ideas que la textualidad no lograba realizar (Castro Gómez, 2009), en la medida en que como imágenes movilizaban ideas y deseos no necesariamente fijos o de fácil traducción y fijación textual, por lo que permitían mostrar e introducir imaginariamente distintos elementos que inclu- 
so aún no existían o estaban en proceso de construcción, así como un modelo corporal que disfrutaba de las maravillas modernas y que podía ser alcanzado por el uso de los productos que se promocionaban. A su vez, la aparición de Margarita se da en un contexto de proliferación de medios de comunicación escritos donde la femineidad y la juventud eran moldeadas y a la vez perseguidas como ideales, y las revistas funcionaban como espacios donde se ponía en discurso una imagen cultural adecuada a ello. De esa forma las imágenes publicitarias y los artículos en su interior refuerzan los discursos sobre juventud que se están instalando como hegemónicos en la esfera cultural chilena. Como se ha dicho anteriormente, si bien Margarita ha sido tomada como una revista femenina (Ledezma, 2005; Pérez y Godoy, 2009) esta engloba y articula las necesidades de las nuevas identidades modernas que durante las primeras décadas del siglo se habían comenzado a constituir y que para 1934 (momento que surge esta revista) eran grupos claramente delimitados y reconocidos en la sociedad como lo son las jóvenes.

A partir de lo anteriormente expuesto, se presentará el análisis realizado a las imágenes publicitarias de Margarita que utilizaron las ideas de cuerpo y edad como estrategia comunicativa y que aluden a ello en texto e imagen. En el análisis se realizó una lectura semiótica a las imágenes publicitarias rescatando así los planos de representación de la visualidad y textualidad, lo que permitió una descripción y categorización para una posterior interpretación.

En términos generales, el trabajo con las imágenes publicitarias contempló la revisión de la revista Margarita durante la década de $1930{ }^{2}$ En un segundo momento se construyó un banco de imágenes de la revista y se seleccionó para la lectura de imágenes aquellas que explícitamente a partir de sus textos aludieran a temáticas vinculadas con la edad y/o juventud, y con el cuidado del cuerpo. A partir de ello, se seleccionaron diecisiete imágenes publicitarias que refirieron a cuerpo y edad, y que fueron la base para la descripción y posterior categorización.

En términos del análisis descriptivo se reconoció en cada imagen publicitaria la espacialidad y la composición de la pieza para conocer los mecanismos formales de transferencia de significado entre objetos, palabras e imágenes (Rose, 2012). Esto se llevo a cabo en cada una de las imágenes publicitarias reconociendo así el mensaje visual caso a

2 Si bien la revista tiene una duración hasta la década de 1950, se contempló revisar solo su primera época de aparición por un criterio metodológico e interés en la década de 1930. 
caso (Joly, 2003). Posteriormente se construyeron categorías de manera sustantiva con aquellos elementos en común que las imágenes transmitían - que contemplaron desde las características de los dibujos/fotos, los productos, los atributos y espacialidad, hasta los enunciados y la caligrafía - y que sirvieron para la interpretación de las características y atributos que se presentaban para las mujeres jóvenes en esta revista. Desde allí que se rescate y presente en este artículo, que las características y atributos que son identificados al hablar de jóvenes mujeres durante la década de 1930 en la revista Margarita constantemente hablen de cuerpos que idealizan la delgadez, belleza y blancura. Por último, se reconoció en esta descripción las estrategias comunicativas utilizadas en la publicidad, y que se presentan en este artículo como mecanismos de amenaza y gratificación, ya que se reconocen estos dos modos como los más utilizados en la publicidad de la revista.

\section{ATRIBUTOS DEL CUERPO JUVENIL: BELLEZA, DELGADEZ Y BLANCURA}

Uno de los discursos más recurrentes encontrados en la publicidad de la revista Margarita durante su circulación en la década de 1930 fue aquel que idealizó el cuerpo juvenil. En gran cantidad de páginas se promovieron ideas acerca del cuerpo, su belleza y cuidado, con énfasis en la juventud y femineidad, utilizando formatos que iban desde los cuentos hasta la publicidad. Con el propósito de reconocer los atributos que definieron en aquel tiempo y medio al cuerpo juvenil, así como interpretar las estrategias utilizadas por estas imágenes publicitarias para fijarlos, es que se realizó una lectura semiótica de las imágenes publicitarias y se presentan aquí los resultados.

De modo general, se reconoce que el diseño utilizado por los publicistas al interior de la revista permite identificar diferentes tipos de imágenes publicitarias según tamaño y estilo. Las técnicas utilizadas variaban y había uso de fotografías, dibujos, recuadros solo con textos y páginas de reportajes publicitarios. En relación a la dimensión cromática de dichas imágenes, en su mayoría son en blanco y negro y solo las contraportadas traían imágenes publicitarias con colores. Las figuraciones de cuerpos femeninos fueron los referentes en el uso de los productos y el modelo de mayor representatividad en las imágenes publicitarias de Margarita. 


\section{a) La belleza natural de la juventud}

La belleza como atributo es uno de los elementos más representados y aludidos en la publicidad para caracterizar al cuerpo juvenil. Si bien la belleza es culturalmente construida y se caracteriza por la relatividad local e individual de su interpretación, estamos ante un momento histórico de disputa por los modelos de representación entre los referentes norteamericanos que principalmente dictaminan los cánones de belleza a nivel global tal como señala Fernando Purcell (2012) y la herencia del modernismo europeo que aún estaba presente en la construcción estética de la publicidad. Sea cual fuere el modelo que sustenta la imagen publicitaria en esta revista, en término generales, la belleza fue asociada a una idea de juventud y femineidad.

La publicidad de Margarita pone en evidencia la relación que se promociona como la correcta: cuidado corporal, juventud y belleza. En las imágenes publicitarias que se revisaron y dan cuenta de esta relación, se observa un patrón escrito y visual similar para dar cuenta de este tipo de representación. En los textos se leen palabras como «armonía» «belleza», «juventud», «naturaleza»y «primavera», que se relacionan de manera estructural; es decir, si una cambia las demás también se ven afectadas, por lo que si una se cuida se refuerzan las demás. Los textos publicitarios funcionan entregando una información con características positivas, que vincula el uso de productos con un sujeto ideal y un resultado esperable universal.

Desde el discurso publicitario se potencia la idea de cómo la belleza se tiene de manera innata, natural, y llega a los cuerpos en un determinado momento, aquel de la juventud o denominado análogamente como primavera. ${ }^{3}$ De esa forma los productos ofertados solo buscan realzar, acompañar y potenciar esta condición natural de belleza que el cuerpo joven posee inherentemente. Es interesante que lo que permita la articulación de sentido en los texto muchas veces tenga que ver con productos para la limpieza, que vincula belleza y juventud con un acto de higienización.

En cuanto a los elementos visuales encontrados en la publicidad de Margarita, se puede decir que los productos, espacios y accesorios con que las jóvenes se retratan, remiten en términos generales a la idea de campo, naturaleza y primavera por un lado, y por otro al cuidado en la

3 Referencia: «Jabón Flores de Pravia». Revista Margarita, 4 marzo de 1937:57. Sección Revistas 12 (31-10). Santiago: Biblioteca Nacional. 
intimidad a partir de actos de arreglo corporal. Las publicidades que promocionan productos para realzar la belleza — que van desde cremas, pinturas y vestimentas - muestran a las jóvenes de perfil y usando accesorios que buscan presentarla con una estética natural, menos sofisticada y producida que otras mujeres de la publicidad de Margarita.

En Margarita pudimos reconocer la belleza como un atributo universal vinculado típicamente al cuerpo juvenil. De esta forma, las jóvenes son las que ostentan en sociedad la cualidad de la belleza como algo natural. En el ámbito del discurso esta idea se desplegó de manera circular, esto quiere decir que ser joven garantizó la belleza y la mujer bella fue generalmente la joven, mientras que la publicidad enfatiza esta condición y propone una serie de productos y acciones para «revelar»o «hacer notar» aquello. En la publicidad hay una discursividad que alude a una belleza que no se debe crear, sino que está innatamente en el cuerpo juvenil, y a partir de un correcto uso de algunos productos y limpieza del cuerpo, permitirá la visibilidad e idealización propuesta. A partir de esto es que podemos decir que el atributo de belleza tuvo un destinatario poco cambiante y se instaló y naturalizó hasta nuestros días.

\section{b) La delgadez como talla ideal del cuerpo joven}

La delgadez es el segundo atributo que más se relaciona con el cuerpo de juventud. Según Y. Cabrera (2010) la relación delgadez y mujeres es uno de los temas más tratados en la publicidad y se ha estudiado mucho desde los años 1980, con un énfasis en las posibles influencias de estos discursos en un público juvenil/adolescente y en mujeres con trastornos alimenticios. En las imágenes de la revista Margarita la delgadez fue uno de los atributos predominantes en la definición del cuerpo juvenil, pero en los años treinta, lo que de inmediato permite cuestionar que esta temática sea algo propio de la modernidad tardía, y más bien invita a reflexionar sobre la «talla ideal», como un fenómeno mucho más antiguo de lo que se imagina.

Las imágenes publicitarias que trataron la relación juventud y delgadez, indican un mensaje textual que refiere al bajo peso como talla ideal, y las imágenes que utilizan muestran todo el cuerpo como forma de representar el cuidado y la delgadez, ya sea alcanzada o deseada. La delgadez como atributo no está asociada a una parte corporal específica - como el atributo de la belleza, que por ejemplo se asocia principalmente a los rostros bellos de las jóvenes que son retratadas - y se presenta una visión completa del cuerpo, generando una 
construcción visual de la talla ideal enfatizando cuál es el contorno corporal correcto y definido para la juventud.

A su vez, las publicidades sobre delgadez muestran una relación que se establece entre objetos y cuerpos. Esto muchas veces puede notarse a partir de los envases que contienen los productos publicitados — y como ellos están abiertos — siendo por lo tanto un mensaje que transmite que su uso será aquello que produce resultados de transformación en los cuerpos. Así las imágenes promueven una vinculación entre producto abierto y usado, con el cuerpo joven y delgado. Se observa también en esta época la promoción de «pastillas para adelgazar» como productos eficaces para lograr la talla ideal. ${ }^{4}$ De esta forma la imagen no solo indica un atributo, sino que también nos orienta en la comprensión de aquel proceso de medicalización que autores como Nicolás Fuster (2013) han señalado que ocurrieron en Chile desde mediados del siglo XIX y las primeras décadas del XX, a partir de la promoción de discursos y prácticas farmacéuticas y médicas. En ese sentido, el discurso publicitario puso en un registro cotidiano, popular y simple, la idea moderna de cómo la ciencia se debe incluir en el mejoramiento de la vida, en otras palabras,

como un dispositivo de normalización, así como de reconocimiento básico y comercial de aquellos saberes que se instalaban en la sociedad chilena como indispensables para el desarrollo de la vida.

En cuanto a los diversos mensajes de carácter lingüístico que se encuentran en la publicidad, observamos al menos dos estrategias persuasivas diferentes para referir a la delgadez y juventud. Por un lado, un mensaje que alude a la gordura cuyos mecanismos visuales de persuasión son dibujos que infunden miedo: un miedo a ser gorda y representada por fuera de estos cánones de belleza que se están instalando como los correctos; y por otro lado hay un tipo de mensaje positivo del estilo «eres bella porque eres delgada», lo que refuerza la idea juventud/delgadez como una posibilidad real, rápida y accesible. Son dos estrategias del lenguaje publicitario que de maneras diferentes permiten fijar la idea de la delgadez/juventud como forma accesible para estar bien.

4 Referencia: «La juventud», Revista Margarita, 10 marzo de 1938. Sección Revistas 12 (30-16). Santiago: Biblioteca Nacional. 
A partir del análisis de imágenes de la revista Margarita en la década de los años treinta, se puede decir que la delgadez tiene una historia y arraigo temprano en la publicidad. La delgadez se presenta como el ideal de un cuerpo juvenil y la talla que debe ser alcanzada por las mujeres. Esta delgadez no estaba asociada necesariamente con un régimen alimenticio en particular; es decir, la industria alimenticia no proporcionaba la matriz desde la cual se desprendían estas idealizaciones y atributos, y serán los sectores de la moda y la farmacéutica principalmente, desde donde se despliegan conocimientos y discursos sobre la necesidad de que el cuerpo femenino y juvenil fuese delgado.

\section{c) Jóvenes blancas: modelos raciales y cuerpos juveniles}

Un tercer atributo asociado a las jóvenes se relaciona con la necesidad y universalidad de sus cuerpos blancos, discurso que se operacionalizó y/o comprendió masivamente a partir de la idea de claridad o cabello rubio y la limpieza. Este atributo se manifiesta visualmente por el tipo de cuerpo retratado o simplemente dibujado en las imágenes publicitarias. En la mayoría de imágenes de la revista usaron la mujer blanca como modelo por excelencia para representar las distintas cualidades y atributos del cuerpo bello, delgado y juvenil.

La caracterización del cuerpo blanco en la mayoría de las publicidades en Margarita, fue algo que se utilizó de manera «natural», aún frente a una población que no tenía aquellos rasgos fenotípicos de manera generalizada, por lo que fomentar su blancura fue un acto que buscaba presentar aquel color como el correcto. La blancura, «rubiedad», claridad e incluso la limpieza fueron las formas de expresión, desde el discurso publicitario, de la matriz discursiva sobre la raza que era vigente en Chile, y que mantuvo coherencia y conexión estructural con los atributos del cuerpo juvenil. ${ }^{5}$

Los textos publicitarios proponen en términos generales la vinculación entre el cuerpo que se cuida y limpia, con un cuerpo blanco, por lo que se vincula el deseoso cuerpo blanco y juvenil principalmente a prácticas de uso diario y de higiene del cuerpo. Así, los mensajes connotan los sentidos de blancura y raza en la medida en que las palabras juventud-blanca se relacionan con palabras como perfección, inmacu-

5 Referencia Imagen publicitaria «Manzanilla Verum», Revista Margarita, 3 octubre de 1935:87. Sección Revistas 12 (30-4). Santiago: Biblioteca Nacional. 
lada, superioridad, belleza y rapidez, todas inscritas dentro de un registro cultural validado como positivo y deseable, por lo que las palabras vinculadas con la relación blancura e higiene, presentan la idea de superioridad de la raza blanca. ${ }^{6}$

En las imágenes publicitarias que aparecen en Margarita para retratar a jóvenes mujeres, las presentan con una tez blanca y cabello castaño o rubio, ya que el color negro no se utilizó de manera frecuente. La blancura, como uno de los atributos vinculados a la corporalidad juvenil, puede ser comprendida como resultado de prácticas y discursos sociales que buscaron blanquear a los sujetos del Chile de la década de 1930 a partir de la limpieza. La puesta en escena de determinados modelos en imágenes con una utilización de rostros con características blancas, lograba idealizar y proponer modelos con una marcada herencia e imaginario colonial como los deseables. De esta forma, las relaciones de imágenes y textos logran fijar y construir determinadas imágenes juveniles. La ausencia de jóvenes morenas o indígenas, por ejemplo cuando se alude a la juventud, permite entender sobre qué cuerpo se edificó la construcción visual de esta idea de juventud.

\section{DISCIPLINAMIENTO DE LOS CUERPOS JUVENILES UTILIZADOS POR LA PUBLICIDAD}

El análisis de las imágenes publicitarias de Margarita permite dar cuenta de las estrategias comunicativas, culturales y contextuales utilizadas para nombrar y fijar atributos. A partir de su forma y contenido, reconocimos en las imágenes publicitarias al menos dos estrategias de carácter disciplinar que funcionaron para la exitosa fijación de los discursos e imágenes sobre el cuerpo juvenil: las amenazas y las gratificaciones.

En cuanto a las «amenazas» observamos que en la publicidad de Margarita no hubo mayores inconvenientes en utilizar el miedo que producían ciertas características corporales para vender los productos. Las amenazas estaban dirigidas principalmente a no poder tener un cuerpo que ya se perfilaba como el correcto, deseable y normal. A su vez, encontramos estrategias comunicativas distintas para producir amenazas, algunas más enfáticas y directas que otras. Por ejemplo, en los encabezados de las imágenes aparecían frases como «iTengo miedo

6 Referencia «La Milo», Revista Margarita, 5 junio de 1936:77. Sección Revistas 12 (30-7). Santiago: Biblioteca Nacional. 
a envejecer!» o «Que la gordura no tape tu juventud», ${ }^{7}$ donde será el miedo aquel que funcione en sentido amenazante, relacionándose directamente con un atributo que no es deseable ni favorable para la joven.

Otro tipo de estrategia fue más sutil en entregar el mensaje, aunque no menos efectiva. Así hay publicidades que apuntan a preguntas como « $¿$ Tiene usted un cutis que le queda bien con un vestido elegante, o tiene que ocultarse en las sombras por tener su cutis ajado y con arrugas?» «Ojos que acusan: El hombre de hoy día es juzgado, en muchos casos, por el aspecto de su esposa o novia». ${ }^{8}$ Este tipo de mensaje publicitario se repite en la publicidad de Margarita, y al aparecer muchas veces, logra saturar y así ser efectivo como mecanismo de promoción de una determinada acción y/o producto.

De esta forma las amenazas que afectaron una idea de cómo el cuerpo femenino y juvenil debía ser, funcionaron gracias a un segundo ejercicio discursivo y publicitario que es el de la «gratificación». Es difícil sostener, después de revisar las imágenes, que solo el miedo pudo ser el motivo por el cual ciertas ideas y prácticas del cuidado de sí se fueran instalando comunicacionalmente, y así reconocemos que fueron las recompensas que prometían estos productos y que es lo que hemos denominado como gratificación, ${ }^{9}$ lo que completaba el despliegue de esta discursividad asociada al cuerpo.

Observamos que para un mismo tipo de productos hay diferencias y no se utiliza solo el miedo sino también la garantía de que al usarse se podrá ostentar el atributo deseado. De esta forma, las gratificaciones o recompensas que entregó la publicidad estuvieron ligadas directamente a promocionar los tres atributos - belleza, delgadez y blancura - y relacionarlos directamente con la idea de juventud y femineidad. A su vez, los modelos en imágenes que se presentaron en este medio, rescataron o crearon un modelo directamente vinculado a imá-

7 Referencia: «Tengo miedo de envejecer», Revista Margarita, 21 abril de 1938. Sección Revistas 12 (30-16). Santiago: Biblioteca Nacional. «La gordura irá tapando su juventud», Revista Margarita, 24 marzo de 1938. Sección Revistas 12 (30-16). Santiago: Biblioteca Nacional.

8 Referencia: «¿Su cutis?», Revista Margarita, 7 febrero de 1935:47. Sección Revistas 12 (30-3). Santiago: Biblioteca Nacional. «Ojos que acusan», Revista Margarita, 7 marzo de 1935:58. Sección Revistas 12 (30-3). Santiago: Biblioteca Nacional.

9 Referencia: «Kissinga», Revista Margarita, 5 diciembre de 1935:67. Sección Revistas 12 (30-5). Santiago: Biblioteca Nacional. 
genes norteamericanas o europeas, idealizando un cuerpo como el correcto y prometiéndolo a bajo costo.

Las amenazas y gratificaciones como estrategias comunicacionales de la publicidad, son coherentes a nuestro juicio con un discurso sociocultural de la época ya que sería improbable que los discursos publicitarios «flotaran» de manera arbitraria y más bien, todo lo contrario, sostenemos que son reflejo de lo que culturalmente era aceptable. De esta forma la industria publicitaria solo lo hacía visible y representaba en un registro comercial lo que podía ser pensado para las jóvenes mujeres en aquella época en Chile.

\section{CONCLUSIONES}

La centralidad del análisis propuesto identificó e interpretó cómo se configuró una imagen e idea del cuerpo femenino y juvenil a partir del reconocimiento de atributos y sus estrategias de anclaje cultural en el análisis de las imágenes publicitarias de los años 1930 en Chile. Los atributos que se encontraron en la publicidad de Margarita responden a una delimitación, caracterización e idealización del cuerpo de las jóvenes y que de base tuvo la delgadez, la blancura y la belleza como el modelo corporal deseable. Estos tres atributos se articulaban entre sí para definir cómo era y debía ser el cuerpo de las jóvenes.

La publicidad de la revista Margarita analizada ayuda a replantearse la idea de que los atributos juveniles hegemónicos como la blancura, belleza y delgadez son un fenómeno tardío de la modernidad, a la vez que permiten sostener que funcionaron tempranamente en la definición de una idea de juventud. Creemos que el papel de las imágenes y los reportajes de estas revistas revelan una serie de conocimientos sobre las jóvenes y su rol en la sociedad. La importancia de atender este tipo de fuentes se debe a que en ellas se encuentran también los vestigios de cómo se ha venido construyendo una discursividad reguladora de las prácticas, conductas y actitudes de estos cuerpos, que tiene mayor importancia en la medida que ha trascendido y perdurado durante el tiempo, afianzándose como identidades hegemónicas que son incuestionables.

Finalmente, reconocer el cuerpo como eje central para el análisis de la construcción cultural de la juventud permite a su vez abrir el debate sobre qué cuerpos son los más estudiados y representados por los campos de estudios culturales en juventud, e invitar a preguntarse por estos otros cuerpos muchas veces invisibilizados en el discurso acadé- 
mico u olvidados en las páginas de viejas revistas que no todos se animas a revisar. El cuerpo de las jóvenes invita a reflexionar también sobre los lugares desde donde se pueden enunciar los atributos juveniles y analizar los saberes detrás de estas idealizaciones que formaron parte de la confección o construcción de una juventud femenina chilena.

SANTIAGO (CHILE), JULIO 2014

RECIBIDO: JULIO 2014 ACEPTADO: NOVIEMBRE 2014

\section{REFERENCIAS BIBLIOGRÁFICAS}

AGUILERA, ÓSCAR (2009): «Los estudios sobre juventud en Chile: coordenadas para un estado del arte». Última Década $\mathrm{N}^{\circ} 31$. Valparaíso: Ediciones CIDPA.

CABRERA, Yolanda (2010): «El cuerpo femenino en la publicidad. Modelos publicitarios: entre la belleza real, la esbeltez o la anorexia». Revista Icono $\mathrm{N}^{\circ} 14$, Vol. 8.

CASTRO GÓmeZ, SANTIAGO (2009): Tejidos oníricos: movilidad, capitalismo y biopolítica en Bogotá (1910-1930). Colombia: Editorial Pensar.

FEIXA, CARLES (1998): De jóvenes, bandas y tribus. Barcelona: Ariel.

FouCAUlt, Michel (2005): Historia de la sexualidad. I. La voluntad del saber. México: Siglo XXI Editores.

FUSTER, NICOLÁs (2013): El cuerpo como máquina. La medicalización de la fuerza de trabajo en Chile. Santiago: Editorial Ceibo.

García-Huidobro, Ceclia y Paula Escobar (2012): Una historia de las revistas chilenas. Santiago: Ediciones UDP.

Hall, Stanley (1904): Adolescence: Its Psychology and its Relations to Physiology, Sociology, Sex, Crime, Religion and Education. Nueva York: Appleton Century Crofts.

JOLY, MARTINE (2003): La imagen fija. Buenos Aires: La Marca Editora.

LE BRETON, DAVID (2002): La sociología del cuerpo. Buenos Aires: Ediciones Nueva Visión.

LEDEZMA, ANA MARÍA (2005): «La sociedad en vitrina: mujeres en la publicidad. Chile-1950-1960». Tesis. Universidad de Chile.

MCROBbIE, ANGEla y JENNY GARBER (2010): «Chicas y subculturas: una aproximación». En HALL y JEFFERSON (2010) Resistencia a través de los rituales. La Plata: Universidad Nacional de la Plata Ediciones.

PÉrEZ, F. y C. GODOY (2009): «Territorios imaginarios de lo doméstico. Vida cotidiana en las revistas femeninas 1930-1960: el caso de Margarita». Revista Chilena de Antropología Vsisual $\mathrm{N}^{\circ} 13$. Santiago: Ediciones CEAVI. 
PURCELl, Fernando (2012): De película!: Hollywood y su impacto en Chile, 1910-1950. Santiago: Editorial Taurus.

REGUILlO, RoSANNA (2003): «Las culturas juveniles: un campo de estudios; breve agenda para la discusión». Revista Brasileira de Educação №23. Río de Janeiro: ANPED.

Rose, GILlian (2012): Visual Methodologies: An Introduction to Researching with Visual Materials. Londres: SAGE.

TORO, PABLO (2010): «Los espacios de la juventud en Chile en el siglo XIX». Revista Docencia $\mathrm{N}^{\circ} 40$. Santiago: Colegio Profesores.

Urteaga, Maritza (2010): «Género, clase y etnia». En Reguillo (2010): Los jóvenes en México. México, D.F: Fondo de Cultura Económica y Consejo Nacional para la Cultura y las Artes. 